\title{
Design of compact microstrip patch antenna for WBAN applications at ISM $2.4 \mathrm{GHz}$
}

\author{
Shahid M Ali, Varun Jeoti, Tale Saeidi, Wong Peng Wen \\ Department of Electrical and Electronic Engineering, Universiti Teknologi PETRONAS, Malaysia
}

\begin{tabular}{l}
\hline \hline Article Info \\
\hline Article history: \\
Received Jan 14, 2019 \\
Revised April 13, 2019 \\
Accepted May 3, 2019 \\
\hline
\end{tabular}

Keywords:

Impedance bandwidth

ISM band

Patch antenna

SAR

WBAN

\begin{abstract}
This paper introduces the design of compact microstrip patch antenna for wireless body area network (WBAN) applications at ISM $2.4 \mathrm{GHz}$. The design consists of a radiating patch on one side of the substrate and a ground plane is located on the other side of the substrate. The antenna is fed through an inset transmission line and then loaded by two triangles, and shorting pins on both sides of the radiating patch to lengthen the path for current, as result it reduced the overall size. The dimensions of radiating patch antenna are $62 \mathrm{~mm} \times 43 \mathrm{~mm} \times 1.67 \mathrm{~mm}$. By locating the proposed antenna On and Off body communication, it can maintain compact and stable far field radiation characteristics and negligible specific absorption rate (SAR). Furthermore, high efficiencies of about $53 \%$ and $46 \%$ are obtained during off and on body, which is higher than recent similar works in the literature. The simulated results showed a good agreement with the measured results. Owing to the acceptable results, the proposed design can be a reliable candidate for WBAN applications at ISM band.
\end{abstract}

Copyright () 2019 Institute of Advanced Engineering and Science. All rights reserved.

\section{Corresponding Author:}

Shahid Muhammad Ali,

Department of Electrical and Electronic Engineering,

Universiti Teknologi PETRONAS,

Bander Seri Iskandar, 32610 Tronoh, Perak, Malaysia.

Email: shahid_17006402@utp.edu.my

\section{INTRODUCTION}

Recently, the wireless body area networks (WBAN) are progressing swiftly. As The wireless body area network is a new developed wireless communication technology which is used for wireless communication In and On and Off a human body wirelessly like health monitoring for different age peoples, tracking, observing human vital signs, physical training, tracking and emergency rescue systems [1]. For health application, it is able to offer continuous and unobtrusive monitoring and sensing for healthcare In and On human bodies of different factors such as ECG,EEG,PH, temperature, blood pressure, level of patient etc. [2-5]. For On body wireless communication system, the system is continuously demanded to be lightweight, small, flexible, low profile, robust as well as capable of unobtrusive and continuous monitoring, all of which must mentioned the reliable communication with high performance. One of the key issues associated with the device and circuit of body area network (BAN) is the suitable design of antenna, as the system requirements are directly related to the antenna performance, according to the link budget. Usually it is used to transfer sensor data wirelessly to the nearest central station $[4,5]$.

In fact, when an antenna is kept near to a human body, the degradation of antenna performance is inevitable. For instance, the input impedance and resonant frequency of the antenna will be significantly influenced by capacitive coupling between the body and antenna. The antenna can also suffer from reduced radiation efficiency due to bulk power absorption by the body. Also, depending on the propagation condition, the radiation pattern can be considerably distorted [3,4]. As a result, these phenomena can increase the transmission errors or, may be cause a loss of marginal communication link [5] in case of extreme case. 
To obtaining a good and reliable performance of an antenna, it should be insensitive to the proximity effect to the human body an also needs to have minimum radiation towards a human body. But, when an omnidirectional antenna placed near to a human body, as a result the radiation efficiency is significantly reduced. Thus, the antenna having unidirectional radiation pattern is suitable choice for In and On and Off body communication to minimize the effects of the human body and reduce body exposure to electromagnetic radiation (EM), it should be insensitive to the proximity effect to human body and needs to have a minimum radiation toward a human body [6].

However, it is cleared that the antenna polarization is typically required in normal direction to the body surface for on body communication. Thus, the patch antenna is considered as an important device in body area network due to its low profile, low cost, planar structure, easy to fabricate as well as provide unidirectional radiation pattern [7, 8]. A large ground which is placed under the patch; it is essentially used to reduce the mutual coupling between the human body antenna and as a result it enhances forward radiation at the bore sight. These studies presented that the SAR and radiation characteristics were not only enhanced but also the directional pattern could be obtained using ground on the back side of the monopole type antenna [9]. However, all these previous works are not suitable for practical for BAN applications due to their bulky size and rigidness and complicated manufacturing procedures.

Generally, there are several designs have been studied and tested by researchers as a wearable antenna like cavity-backed [10], microstrip [11], inverted-F [5, 12], planar, and vertical monopole antennas [13]. However, all these antennas have suffered due to the large footprint, narrow bandwidth, and high frontto-back ratio (FBR). It has emphasized that the aim of this paper is to design a small dimension microstrip patch antenna for wearable applications due to its planar, versatile structure and provide broader dimension for the electromagnetic waves. The result showed a stable radiation characteristic for off and on body at 2.4 GHz. Hence, it can be deployed for continuously monitored the bio signals in the real-life scenarios.

This paper is organized as follows: Section.2 describes the proposed antenna design. Section.3 expands upon the result and discussion about the Off and On Body communication. Section. 4 and 5 provides conclusion and references.

\subsection{Comparison of Proposed Antenna with Literature}

However, the antenna is compared to the similar antennas in the literature in Table 1. Thus, it features small dimensions and reaches the highest efficiency and stable far field radiation characteristics in the $2.4 \mathrm{GHz}$ ISM Band, respectively.

Table 1. Comparison Between Proposed Antenna and Similar Antennas in the Literatures

\begin{tabular}{|c|c|c|c|c|}
\hline S.no & Band $\mathrm{GHz}$ & Dimension $\left(\mathrm{mm}^{3}\right)$ & SAR(w/kg) & Efficiency $\%$ \\
\hline [14] & 2.4 & $46 \times 46 \times 2.4$ & 6.19 (W/EBG) & N/A \\
\hline [15] & 2.4 & $202 \times 115 \times 0.01$ & N/A & 48 \\
\hline [16] & 2.4 & $100 \times 100 \times 4.975$ & 0.58 & 42 \\
\hline [17] & 2.4 & $60 \times 60 \times 6.34$ & $0.66 / 0.18$ & 51.4 \\
\hline [18] & 2.4 & $100 \times 100 \times 3.34$ & 0.05/0.01 (CRLH) & $38 / 45$ \\
\hline [19] & 2.4 & $100 \times 100 \times 3.34$ & 0.046 & 50 \\
\hline [20] & 2.4 & $70 \times 70 \times 0.237$ & N/A & N/A \\
\hline [21] & 2.4 & $119 \times 184 \times 3.34$ & N/A & N/A \\
\hline [22] & 2.4 & $88 \times 142 \times 1.34$ & N/A & N/A \\
\hline [23] & 2.4 & $121.9 \times 109.1$ & N/A & -8.11 \\
\hline [24] & 2.4 & $75 \times 75 \times 1.34$ & N/A & N/A \\
\hline [25] & 2.4 & $80 \times 98$ & $>2 \mathrm{~W} / \mathrm{KG}$ & 3.3 \\
\hline [26] & 2.4 & $114.5 \times 101 \times 2.34$ & N/A & 48.75 \\
\hline Proposed & 2.4 & $62 \times 43 \times 1.67$ & $0.44 \mathrm{~W} / \mathrm{KG}$ & $53 / 46$ \\
\hline
\end{tabular}

\section{ANTENNA STRUCTURE}

A final design of proposed microstrip patch antenna was fabricated, shown in Figure 1 (b), which can be attached directly to the human body to constantly measure the vital signals of an individual like patients or athletes, shown in Figure 1(c).

The patch and the ground of the antenna are constructed using a 0.035-mm-thick copper [27] with an approximated conductivity of $1.18 \times 105 \mathrm{~S} / \mathrm{m}$. The antenna substrate is a nonconductive material with 1.6$\mathrm{mm}$ thick FR-4 [28]. Its relative permittivity and loss tangent are 4.3 and 0.025 , correspondingly. The overall size of the antenna is $62 \mathrm{~mm} \times 43 \mathrm{~mm} \times 1.67 \mathrm{~mm}$ at $2.45 \mathrm{GHz}$, which is the smallest size in the reported Table.1. In addition to that, the two triangular offsets are introduced to radiating patch, which is also shortcircuited to the ground by using shorting pins. The antenna is loaded by these pins and triangular offsets to 
improve the antenna performances in radiation characteristics and to miniaturize the patch, the current path was lengthened by realizing the compound shape with a shorting pin to the ground. Cooperating with the reflection of the ground, the long rectangular path work in the $1 / 2$ wavelength resonance mode, which increase the radiation outward and reduce the undesired back radiation towards the body. The reason that another triangular is used to the opposite side of the first one, is to further miniaturize the patch and change the current flows. Besides, the locations of the shorting pins are optimized based on the surface current and the electric field (the location which has zero E-field) around the patch and load. Thus, this way of working guarantees the stability of the antenna structure when the rest of the antenna deforms. The antenna is fed through inset fed line, though in such type of feeding process, shown in Figure 1 (a), the edge of the microstrip patch is connected directly to a conducting strip. This type of feeding method suggested the benefit that the conducting line can have the opportunity of engraved on same substrate of patch antenna providing a planar shape. Hence, Thus, length of conducting element is smaller as compared to the width of the patch antenna. The detail dimensions of a proposed design are listed in Table 2.

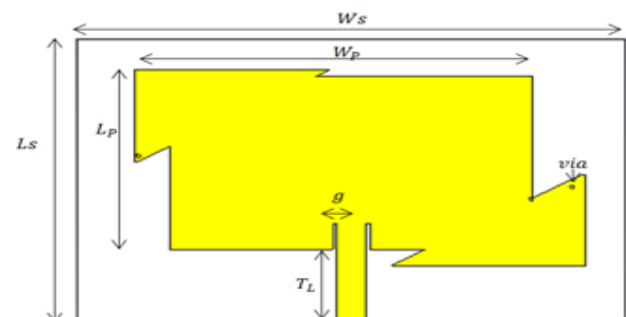

(a)

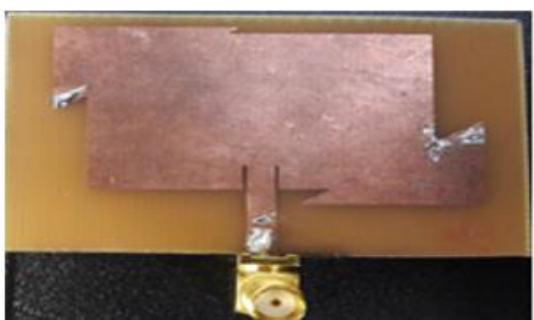

(b)

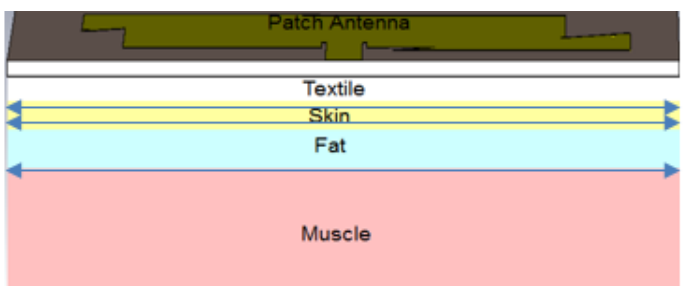

Figure 1. Design of Microstrip patch antenna. (a) Simulated, (b) Fabricated, (c) On Human Mode

The dimensions of the antenna are calculated from the transmission line equations [29].

Step 1) the width of patch calculated by using:

$$
w=\frac{c}{2 f o \sqrt{\frac{(E r+1)}{2}}}
$$

Where $\mathrm{c}$ is the velocity of light, $\mathrm{f}_{0=}$ resonance frequency, $\varepsilon_{\mathrm{r}}=$ Dielectric constant of the substrate Step 2) Calculation of the effective Dielectric constant (creff)

$$
\varepsilon_{e f f}=\frac{\varepsilon_{r}+1}{2}+\times\left(\sqrt{\left(1+\left(\frac{12 h}{w}\right)\right.}\right)
$$

Step 3) Calculation the extension Length: It can be used to calculate the resonant frequency (fc) for Micostrip antenna.

$$
\Delta L=0.412 h \frac{\left(\varepsilon_{r e f f}+0.3\right)\left(\frac{W}{h}+0.264\right)}{\left(\varepsilon_{r e f f}-0.258\right)\left(\frac{W}{h}+0.8\right)}
$$

Step 4) Length of the patch calculated using effective Length (Leff)

$$
L_{e f f}=\frac{c}{\sqrt[2 f]{0} \sqrt{\varepsilon_{\text {reff }}}}
$$




$$
L=L_{e f f}-2 \Delta
$$

Step5) The Ground Dimension for the Antenna: The length and width of the ground plane is calculated using the following,

$$
\begin{gathered}
L_{g}=L+(6 h) \\
W_{g}=W+(6 h)
\end{gathered}
$$

Thus, the proposed antenna is operated as Microstrip patch antenna with ground plane, which worked as shielding for the back-ward radiation. Thus, by varying the width and length of the patch antenna, the antenna can be adjusted and optimized for the WBAN. Thus, Figure 1 and Table 2 described the final geometry of the proposed Microstrip Patch antenna.

Table 2. Geometrical Parameters of Microstrip Patch Antenna

\begin{tabular}{ccc}
\hline S.no & Dimensions & Values $/ \mathrm{mm}^{3}$ \\
\hline 1 & Over All Antenna Size & $62 \times 43 \times 1.67 \mathrm{~mm}^{3}$ \\
2 & thickness of substrate $(\mathrm{ts})$ & FR4 $(1.6 \mathrm{~mm})$ \\
3 & Patch Size $\left(\mathrm{W}_{\mathrm{P}} \times \mathrm{P}_{\mathrm{L}}\right)$ & $41 \times 26.50 \mathrm{~mm}$ \\
4 & thickness of patch $(\mathrm{tp})$ & Copper $(0.035)$ \\
5 & Transmission Line $\left(\mathrm{T}_{\mathrm{W}} \times \mathrm{T}_{\mathrm{L}}\right)$ & $3.36 \times 14.75 \mathrm{~mm}$ \\
6 & Slot g $(\mathrm{w} \times \mathrm{x})$ & $0.4 \times 4.00 \mathrm{~mm}$ \\
7 & Off set Triangles $(\mathrm{w} \times 1)$ & $22.0 \times 14.00 \mathrm{~mm}$ \\
8 & Shorting Pin $(\mathrm{via})$ & Radius $(0.25)$ \\
\hline
\end{tabular}

\section{RESULTS AND DISCUSSION}

In this paper, the patch antenna is designed for application of WBAN, which is shown in Figure 1. The design antenna is then placed on human sample to check the effect of SAR, which is shown in Figure 6. The human model is designed by using CST MWS and it consists of different layers and thickness such as skin $(2 \mathrm{~mm})$, fat $(8 \mathrm{~mm})$, muscle $(20 \mathrm{~mm})$. Thus, the properties of each layer are summarized in given Table 3 given below.

Table 3. Characteristics of Human Body Tissues[23]

\begin{tabular}{ccccc}
\hline Tissues & $\begin{array}{c}\text { Permittivity } \\
(\in \mathrm{r})\end{array}$ & $\begin{array}{c}\text { Conductivity } \\
(\mathrm{S} / \mathrm{m})\end{array}$ & Loss Tangent & $\begin{array}{c}\text { Density } \\
\left(\mathrm{Kg} / \mathrm{m}^{3}\right)\end{array}$ \\
\hline Skin & 31.29 & 5.0138 & 0.2835 & 1100 \\
Fat & 5.28 & 0.1 & 0.19382 & 1100 \\
Muscle & 52.79 & 1.705 & 0.24191 & 1060 \\
Bone & 12.661 & 3.8591 & 0.25244 & 1850 \\
\hline
\end{tabular}

In this paper, the performance of Microstrip Patch antennas can be discussed into different stages: a) Firstly, the wearable antenna is examined in off body communication at $2.4 \mathrm{GHz}$; b) Secondly, the wearable antenna is placed on the human body to investigate the performance and SAR near to the lossy human body at $2.4 \mathrm{GHz}$.

\subsection{Off-body Performance}

The antenna is designed using CST simulation tool. The simulated and measured reflection coefficients agree well which is shown in Figures 2.The simulated $-23 \mathrm{~dB}$ bandwidth is 104(2.3369-2.443 $\mathrm{GHz}$ ) and measured is $105 \mathrm{MHz}(2.33-2.49 \mathrm{GHz})$. The radiation patterns are compared in Figures 3 given below. The front to back ratio (FBR) is higher in both the $\mathrm{x}-\mathrm{z}$ and $\mathrm{y}-\mathrm{z}$ plane. The gain of the antenna is about $3.01 \mathrm{~dB}$ for off body at $2.4 \mathrm{GHz}$. Moreover, the radiation efficiency is more than $53 \%$ for off body communication, maintained it wider half power beam Width (HPBW) throughout the whole operating band, which shows high stability during operation. Figure 3 shows the radiation pattern of the antenna for both $\mathrm{E}$ and $\mathrm{H}$ field. It's obviously illustrated that all radiation is outwards and negligible back radiation and side lobe occurred. According to the radiation pattern, it has shown that the $\mathrm{H}$ filed is working inside $\mathrm{E}$ filed, as a result $\mathrm{H}$ filed is not changing the path of current for resonance frequency during off body condition. 


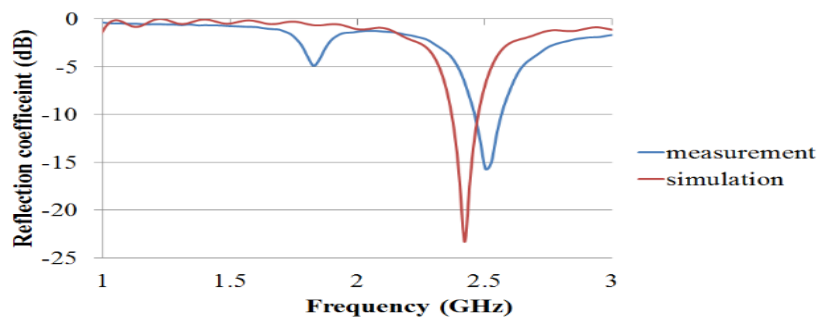

Figure 2. Simulated radiation patterns of antenna in free space at $2.4 \mathrm{GHz}$

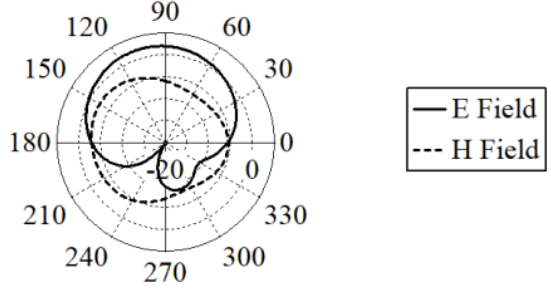

Figure 3. Simulated and measured S11

\subsection{On-body Performance}

The proposed antenna design was simulated and measured on body. It was located on various location of the human body like chest, arm (only chest presented here) etc. Figure 4 shows the simulated and measured reflection coefficients results on body. The bandwidth is larger compared to the off-body communication. This is because of the additional losses because of the proximity of the human body. The $-24 \mathrm{~dB}$ band widths cover the ISM band with a bandwidth of $110 \mathrm{MHz}$ which is acceptable for body area network. For on body application, the efficiency is $46 \%$ and gain is $2.11 \mathrm{~dB}$ on body application, which are still acceptable for wearable applications. Furthermore, the simulation and measurement results are in good agreement. Hence, same trend as off-body radiation pattern is followed by on-body presented in Figure 5. According to the radiation pattern, it has shown that the $\mathrm{H}$ filed is working inside $\mathrm{E}$ filed, as a result $\mathrm{H}$ filed is not changing the path of current for resonance frequency and provided stable radiation pattern during on body condition.

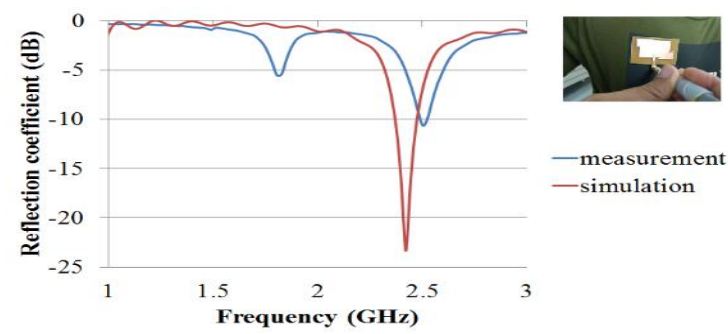

Figure 4. Simulated radiation patterns of antenna On body at $2.45 \mathrm{GHz}$

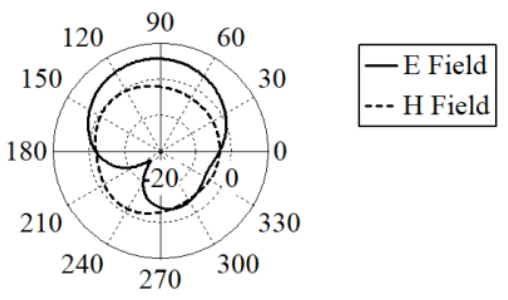

Figure 5. Simulated and measured S11

\subsection{Signal Absorption Rate on Body}

The SAR was simulated using a simplified human model, see Figure 6 . This model consists of 3 layers: a $20 \mathrm{~mm}$ thick muscle layer, a $20 \mathrm{~mm}$ thick, $8 \mathrm{~mm}$ fat layer, and a $2 \mathrm{~mm}$ skin layer. It was placed on real skin. The design antenna input power was set at $0.5 \mathrm{~W}$ (r.m.s). The SAR value was calculated based on the standard of IEEE C95.1 and averaged over 1 or $10 \mathrm{~g}$ of biological tissue. The result shows that the SAR is $0.44 \mathrm{~W} / \mathrm{kg}$ at $2.45 \mathrm{GHz}$. When the input power is $0.5 \mathrm{~W}$ (r.m.s), the maximum SAR value is $0.44 \mathrm{~W} / \mathrm{kg}$ respectively, which is far under the limit of European standard of $2 \mathrm{~W} / \mathrm{kg}$.

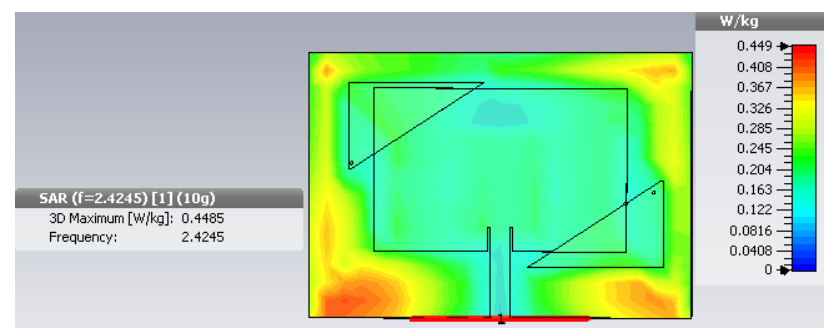

Figure 6. Simulated SAR value of the proposed antenna in free space at $2.45 \mathrm{GHz}$ 


\subsection{Characteristics of the Proposed Antenna}

The design and optimization are done using CST simulation tool. The patch antenna is positioned on top of the sample with a $0.17 \mathrm{~mm}$ textile, to take it wearable, which is shown in Fig. 1(c). The design was finally simulated and measured. In figures 2 and 4, simulated and measured S parameters are given for the off and on body, such as all reflection coefficients are lower than the $-10 \mathrm{~dB}$. The patch antenna given an acceptable bandwidth (105 to $110 \mathrm{MHz}$ ), which is suitable for ISM band applications in both conditions along with stable radiation pattern. The Gain and efficiency of the ON-body state is shifted lower due to the presence of high dielectric constant of human body. Overall, it is realized that the presence of the body does not affect the performance of Microstrip patch antenna. This is due to the full ground plane that provides a good isolation between antenna and body. The Table 4 shows all the basic and important parameters of the proposed design.

Table 4. Summary of the Performance of the Antenna

\begin{tabular}{ccc}
\hline ISM Band & Off Body & ON Body \\
\hline Impedance BW(GHz) & $108 \mathrm{MHz}$ & $105 \mathrm{MHz}$ \\
Gain (dBi) & 3.01 & 2.11 \\
Directivity(dBi) & 5.78 & 5.46 \\
Efficiency (\%) & 53.0 & 46.0 \\
SAR on Body(W/kg) & \multicolumn{2}{c}{$0.44 \mathrm{~W} / \mathrm{KG}$} \\
HPBW(Deg) & 102.3 & 123.5 \\
VSWR & 1.46 & 1.15 \\
\hline
\end{tabular}

Thus, optimizing the antenna and changing the size of element such as length(L), width(W) or using any cap active or inductive components, as a result it changes antenna characteristics. Because any changes in antenna element, it causes changes current distribution. However, any change in the current distribution, it causes changes electromagnetic fields around the antenna. These changes can be occurred in the input impedance, radiation pattern, bandwidth, resonance frequency etc. Thus, analyzing these behaviors that how variation in each element causes changes in the design characteristics, thus it is possible to find the best possible performance for a specific application. Hence, the proposed design is simulated measured and tested for bio signals in the body area network (BAN) at ISM band.

\section{CONCLUSION}

A compact Microstrip Patch antenna for WBAN at $2.4 \mathrm{GHz}$ applications were proposed, simulated, fabricated and measured. The proposed antenna features a very compact size, a good and robust impedance bandwidth performance, and stable far-field characteristics. The SAR value is negligible, according to the standard of FCC and CNIRP regulations due to large ground is existed at the bottom. Both On and Off body communication can be obtained in the $2.4 \mathrm{GHz}$ bands, respectively. The antenna prototype covers the ISM band and a potential candidate for Wireless Body Area Networks (WBAN) applications.

\section{REFERENCES}

[1] S. Yan, "Made To Be Worn," Electron. Lett., vol. 50, no. 6, pp. 420-420, 2014.

[2] G.Fang,E.Dukewicz,M.A Huq, and R.Vesilo, "Medical body area networks:opportunities,challenges and practices, "in Proc.Int.Symp.Commun.Inf.Technol., Oct.2011,pp.562-567.

[3] H.-B.Li et al., "Body area network and its standardization at IEEE802.15.MBAN,". in Proc.16th IST Mobile Wireless Commun.Summit, July.1-5,pp. 1-5.

[4] B.Lo et al, "Body sensor networks-Research challenges and opportunities,"in Proc,.IET Semin.Antennas Propag.Body-Centric Wireless Commun, Apr.24-24,2007,pp.26-32.

[5] G.A.Conway and W.G.Scanlon, "Antenna for over-body-surface communication at 2.45 GHz. IEEE Trans.Antennas Propag. vol.57,no.4,pp.844-855,Apr.2009.

[6] T. S. See and Z. N. Chen, "Experimental characterization of UWB antennas for on-body communications," IEEE Trans. Antenna Propag., vol. 57, no. 4, pp. 866-874, Apr. 2009.

[7] P. J. Soh et al., "A Smart Wearable Textile Array System for Biomedical Telemetry Applications," IEEE Trans. Microw. Theory Tech., vol. 61, no. 5, pp. 2253-2261, 2013.

[8] S. Yan, "Compact All- Textile Dual-Band Antenna Loaded With Metamaterial-Inspired Structure."

[9] H. Xiaomu, S. Yan, and G. A. E. Vandenbosch, "Wearable Button Antenna for Dual-Band WLAN Applications with Combined on and off-Body Radiation Patterns," IEEE Trans. Antennas Propag., vol. 65, no. 3, pp. 1384-1387, 2017. 
[10] R. A. Abd-Alhameed, P. S. Excell, and M. A. Mangoud, "Computation of specific absorption rate in the human body due to base-station antennas using a hybrid formulation," IEEE Trans. Electromagn. Compat., vol. 47, no. 2, pp. 374-381, 2005.

[11] S. Yan, V. Volskiy, and G. A. E. Vandenbosch, "Compact Dual-Band Textile PIFA for 433-MHz/2.4-GHz ISM Bands," IEEE Antennas Wirel. Propag. Lett., vol. 16, pp. 2436-2439, 2017.

[12] T. Mo, Q. W. Lin, X. Y. Zhang, and H. Wong, “A Dual Operating Mode Antenna on Flexible Ground Structures for Wearable Communications," Int. Appl. Comput. Electromagn. Soc. Symp., pp. 1-2, 2017.

[13] J. Zhang, S. Yan, X. Hu, and G. A. E. Vandenbosch, "Aperture-coupled wearable antenna with miniature feeding network," 2017 11th Eur. Conf. Antennas Propagation, EUCAP 2017, pp. 1031-1034, 2017.

[14] S. Yan and G. A. E. Vandenbosch, "Wearable antenna with tripolarization capability," 2017 Int. Work. Antenna Technol. Small Antennas, Innov. Struct. Appl. iWAT 2017, pp. 129-131, 2017.

[15] S. Yan and G. A. E. Vandenbosch, "Wearable pattern reconfigurable patch antenna," 2016 IEEE Antennas Propag. Soc. Int. Symp. APSURSI 2016 - Proc., pp. 1665-1666, 2016.

[16] P. J. Soh, S. Yan, H. Lago, X. Zheng, M. F. Jamlos, and G. A. E. Vandenbosch, "Performance of a textile magnetoelectric dipole operating in the vicinity of the human body," 2016 10th Eur. Conf. Antennas Propagation, EuCAP 2016, 2016.

[17] M. O. Sallam, S. M. Kandil, V. Volski, G. A. E. Vandenbosch, and E. A. Soliman, "2.4/5 GHz WLAN crescent antenna on flexible substrate," 2016 10th Eur. Conf. Antennas Propagation, EuCAP 2016, 2016.

[18] E. F. N. M. Hussin, P. J. Soh, M. F. Jamlos, H. Lago, and A. A. Al-Hadi, "Wideband textile antenna with low back radiation for wearable applications," 2016 URSI Asia-Pacific Radio Sci. Conf. URSI AP-RASC 2016, pp. 1089-1092, 2016.

[19] P. Schilingovski, V. Vulfin, S. Sayfan-Altman, and R. Shavit, "Wearable antennas design for wireless communication," 2017 IEEE Int. Conf. Microwaves, Antennas, Commun. Electron. Syst. COMCAS 2017, vol. 2017-Novem, pp. 1-3, 2018.

[20] I. Agbor, D. K. Biswas, and I. Mahbub, "A comprehensive analysis of various electro-textile materials for wearable antenna applications,” Proc. 2018 Texas Symp. Wirel. Microw. Circuits Syst. WMCS 2018, pp. 1-4, 2018.

[21] B. Mandal, B. Mukherjee, A. Chatterjee, and S. K. Parui, "Design of printed body wearable textile antenna for broadband application,” 2013 IEEE Appl. Electromagn. Conf. AEMC 2013, 2014.

[22] Md.saheb ali, "Design and Optimization of an E shaped wearable antenna in ISM band."

[23] N. Haga, K. Saito, M. Takahashi, and K. Ito, "Characteristics of cavity slot antenna for body-area networks," IEEE Trans. Antennas Propag., vol. 57, no. 4 PART. 1, pp. 837-843, 2009.

[24] A. Alomainy et al., "Statistical analysis and performance evaluation for on-body radio propagation with microstrip patch antennas," IEEE Trans. Antennas Propag., vol. 55, no. 1, pp. 245-248, 2007.

[25] P. J. Soh, G. A. E. Vandenbosch, S. L. Ooi, and N. H. M. Rais, "Design of a broadband all-textile slotted PIFA," IEEE Trans. Antennas Propag., vol. 60, no. 1, pp. 379-384, 2012.

[26] M. N. Suma, P. C. Bybi, and P. Mohanan, "A wideband printed monopole antenna for 2.4-GHz WLAN applications," Microw. Opt. Technol. Lett., vol. 48, no. 5, pp. 871-873, 2006.

[27] U. Ali et al., "Design and SAR analysis of wearable antenna on various parts of human body, using conventional and artificial ground planes," J. Electr. Eng. Technol., vol. 12, no. 1, pp. 317-328, 2017.

[28] G. Kaur, "Wearable Antennas for on - Body Communication Systems," no. 6, pp. 568-575, 2014.

\section{BIOGRAPHIES OF AUTHORS}

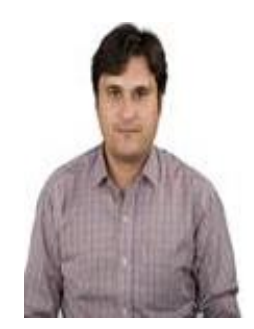

Shahid M Ali is currently a PhD student in Electrical \& Electronic department, Universiti Teknologi PETRONAS (UTP) Malaysia and doing research assistantship. He received his MS degree in Telecommunication Engineering from Sunderland University, UK in June2012. He received his BS degree in Electrical and Electronic Engineering Engineering from University of Engineering and Technology (UET) Peshawar, Pakistan in Jun-2007. He worked as a Field Engineer for 3 years in Egyptian Multinational Telcom Company and worked as a Lecturer/Assistant Director Works in different private/Govt Universities of Pakistan. His research interests are Integrated Wearable antenna design for Body Area Network.

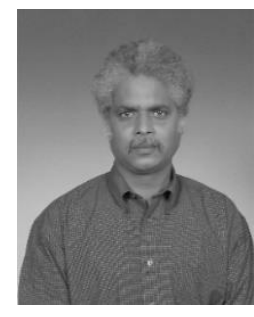

Dr Varun Jeoti received his Ph.D. degree from Indian Institute of Technology Delhi India in 1992. He worked on several sponsored R\&D projects in IIT Delhi and IIT Madras during 1980 to 1989 developing Surface Acoustic Wave Pulse Compression filters, underwater optical receivers etc. He was a Visiting Faculty in Electronics department in Madras Institute of Technology for 1 year during 1989 to 1990 and joined Delhi Institute of Technology for next 5 years till 1995. He moved to Electrical \& Electronic Engineering (E\&E Engg) department of Universiti Sains Malaysia in 1995 and joined E\&E Engg of Universiti Teknologi PETRONAS (UTP) in 2001. His research interests are in Wireless communication technologies, DSL technology and related signal processing, surface acoustic wave devices. 


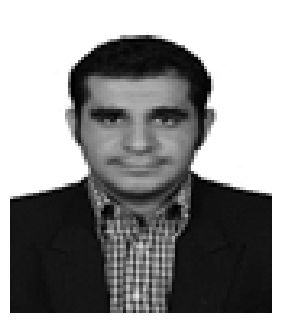

Tale Saeidi is currently a PhD student in the Electrical \& Electronic department, Universiti Teknologi PETRONAS (UTP), Malaysia and doing research assistantship. He received his MS degree in Electrical Engineering from UPM, Malaysia in 2014. His research interests are in Ultra Wide antenna design and Imaging.

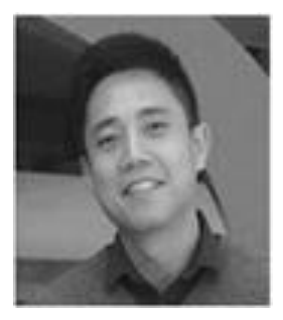

Dr Wong Peng Wen is graduated from University of Leeds in 2005 with BEng (1st Class Hons.) degree in Electrical \& Electronic Engineering. He received Switched Reluctance Drive Award in EE Engineering. He did his PhD study in University of Leeds, UK from 2007-2009. During his $\mathrm{PhD}$, he was involved in UK DTI funded project, developing process design kits for multilayer system-in-package modules. Currently he works as Associate Professor in Universiti Teknologi Petronas and received outstanding researcher award in 2013, publication award in 2014 and Potential Academy Award of the Year in 2015. His research interests include reconfigurable filter, lossy filter design, millimeterwave waveguide filter and passive filter miniaturization techniques. 